\title{
Clinical features and lung function in HIV-infected children with chronic lung disease
} \author{
R P Gie, ${ }^{2} \mathrm{MB}$ ChB, FCP; K Wills, ${ }^{3} \mathrm{PhD}$; M F Cotton, ${ }^{2,4} \mathrm{MB}$ ChB, DTM\&H, FCP, PhD \\ ${ }^{1}$ Faculty of Health, School of Medicine, University of Tasmania, Burnie, Australia \\ ${ }^{2}$ Department of Paediatrics and Child Health, Stellenbosch University, South Africa \\ ${ }^{3}$ Menzies Research Institute, University of Tasmania, Hobart, Australia \\ ${ }^{4}$ KID-CRU Research Institute, Cape Town, South Africa
}

H C Weber, ${ }^{1}$ MB ChB, DCH(SA), MMed (Paed), FC Paed (Cert Pulmonology), Dip Allerg (SA), FRACP, MPH;

Corresponding author: H C Weber (heinrich.weber@ths.tas.gov.au)

\begin{abstract}
Background. Although chronic lung disease (CLD) is commonly seen in children with advanced HIV disease, it is poorly studied. Objectives. To report on the clinical manifestations and lung function tests in children with advanced HIV disease at a tertiary care centre, and determine clinical predictors of poor lung function.

Methods. We undertook a cross-sectional study of children with advanced HIV disease in whom CLD was suspected. We undertook clinical evaluation and lung function tests, accompanied by a retrospective chart review.

Results. In 56 children identified, the median age was 5 (interquartile range (IQR) 2 - 8) years with equal gender ratio. The majority (93\%) had been previously treated for tuberculosis and/or pneumonia (71\%). The most common CLD identified was lymphocytic interstitial pneumonitis (54\%). The median nadir CD4 percentage was 13\% (IQR 8.5 - 16\%) and the median highest reported viral load was $\log 5.8$ (IQR $\log 5.0$ - log6.5). The median duration of antiretroviral therapy was 9.8 (IQR $1.1-19.5)$ months. Lung function tests were performed in 27 (48\%) children. The median forced expiratory volume in 1 second $\left(\mathrm{FEV}_{1}\right)$ was $60 \%$ (IQR 45.3 - 86.3\%) predicted. Previous hospitalisation, respiratory rate, digital clubbing, chest hyperinflation and hyperpigmented skin lesions were associated with a decreased $\mathrm{FEV}_{1}$ in a univariate relationship. In a multiple linear regression analysis, hyperinflation, increased respiratory rate and hyperpigmented skin lesions were associated with poor lung function (percentage $\mathrm{FEV}_{1}$ ).

Conclusion. We identified useful clinical signs predictive of poor lung function in HIV-infected children with CLD, especially in resourcelimited settings.
\end{abstract}

S Afr J Child Health 2015;9(3):72-75. DOI:10.7196/SAJCH.7940

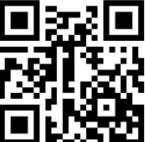

The majority $(>90 \%)$ of paediatric HIV infections occur in sub-Saharan Africa. ${ }^{[1,2]}$ In South Africa (SA), programmes to reduce vertical transmission began in 2003, with combination antiretroviral therapy (cART) becoming available in the public sector in 2004. Many children in whom cART was initiated already had advanced HIV disease. Early ART from 7 to 8 weeks of age was only instituted in $2010 .{ }^{[3]}$ Respiratory disease is a major cause of morbidity and is the most important cause of mortality in HIV-positive children. ${ }^{[4]} \mathrm{A}$ high prevalence of chronic lung disease (CLD) was recently recognised in perinatally infected adolescents. ${ }^{[5]}$

There are no uniform diagnostic criteria for CLD in children. ${ }^{[6-13]}$ Chronic respiratory symptoms such as a chronic cough for at least 3 months of the year, or cough with associated symptoms and chronic radiological signs have been used. ${ }^{[7]}$ In a recent study of CLD in HIV-infected adolescents, the diagnostic criteria for CLD included a combination of symptoms, clinical signs, radiological manifestations, exercise tests, oxygen saturations, spirometry and echocardiographic findings. ${ }^{[5]}$ In this study, at least a third of patients with chronic respiratory impairment would not have been identified had cough-predominant diagnostic criteria been used. Many diagnostic investigations required to substantiate the diagnosis are often unavailable in the areas most affected by HIV. Also, tests to separate cardiovascular from respiratory causes cannot always be performed. Additional clinical predictors of chronic respiratory impairment could be useful in resource-limited settings to enable healthcare workers to recognise children with CLD.
There are a few studies of CLD in HIV-infected children and adolescents. In a narrative review, the most likely aetiologies included pulmonary tuberculosis (PTB), lymphoid interstitial pneumonitis (LIP), persistent or recurrent pneumonia and bronchiectasis. ${ }^{[12]}$ More recently, small airway disease has been described in adolescents. ${ }^{[5]}$ Other aetiologies include interstitial lung disease (ILD) and malignancy ${ }^{[12]}$ In a study by Jeena et al., ${ }^{[7]}$ predating cART availability, $71 \%$ of young children investigated for persistent lung disease (defined as persistence of clinical and radiological findings after at least 1 month of initial treatment) were HIV-infected. In those with symptoms for more than 3 months, LIP (57\%) was the most important cause, followed by PTB (29\%). A review of the chest radiographs of HIV-infected children in the USA, again predating early cART, showed that chronic radiological changes had a cumulative incidence of $33 \%$ by 4 years of age. ${ }^{[11]}$ More recently, Pitcher et al.$^{[14]}$ showed that in children with a median age of 23.8 months and limited access to cART, only $16 \%$ of 330 children from Cape Town had normal chest radiographs, with 169 (51\%) having severe radiological abnormalities.

\section{Objective}

To describe the symptoms, signs and lung function in HIV-infected children evaluated for CLD seen at Tygerberg Children's Hospital in Cape Town, Western Province, SA, a region with a high prevalence of both HIV and TB.

\section{Methods}

Subjects in whom CLD was suspected because of chronic symptoms and/or signs or with a history of recurrent pneumonia participated 
in a cross-sectional study. Clinical evaluation and lung function tests were accompanied by a complete retrospective chart review. The clinical evaluations were performed over 10 months, from May 2005 to February 2006. The definition used for CLD disease was a chronic cough and/or respiratory or radiological signs present for at least 3 months. Vital signs were obtained from the clinical charts on the same day that a single investigator ( $\mathrm{H} \mathrm{C}$ Weber) undertook the clinical examination. Transcutaneous oxygen saturation measurements were not consistently taken and were therefore excluded from analysis. The World Health Organization (WHO) growth standards were used for weight-for-age $z$-scores (WAZ), height-for-age $z$-scores (HAZ) and weight-for-height $z$-scores (WHZ). Children with $z$-scores two standard deviations (SDs) below the mean WAZ were classified as underweight and two SDs below the mean HAZ were classified as stunted. ${ }^{[15]}$ The lowest recorded CD4 percentage and highest recorded log viral load (VL) were obtained from clinical records.

A Jaeger Masterscreen pneumotachometer system (Erich Jaeger, Germany), with daily volume calibration as per American Thoracic Society (ATS)/European Respiratory Society (ERS) protocol was used for lung function tests. ${ }^{[16]}$ Ability to perform adequate lung function tests was determined by the child's ability to produce an acceptable flow volume loop according to ATS/ERS criteria. ${ }^{[16]}$ The highest forced expiratory volume in 1 second $\left(\mathrm{FEV}_{1}\right)$ value was recorded and Polgar's equation was used to calculate reference values. ${ }^{[17]}$

Background and clinical characteristics were summarised using frequency and percentage for categorical data, and median and interquartile range (IQR) for continuous data. A respiratory rate ratio was developed to allow comparison of respiratory rates across different age groups. Each child's respiratory rate was divided by the upper limit of normal respiratory rate for that age. ${ }^{[18]}$

Spearman's correlation coefficients were used to measure the associations between the percentage predicted $\mathrm{FEV}_{1}\left(\mathrm{FEV}_{1} \%\right)$ and clinical characteristics measured on a continuous scale. For continuous variables, mean $\mathrm{FEV}_{1} \%$ was compared using $t$-tests. Univariable and multivariable linear regressions were used to determine predictors for poor outcome in lung function tests. Factors most strongly associated with $\mathrm{FEV}_{1} \%$ in univariable analysis were retained for the multivariable analyses. The data were entered into an Access (Microsoft, USA) database, and all the statistical procedures were performed using STATA statistical software, version 10 (StataCorp, USA). Tests of significance were two-tailed, and a $p$-value $<0.05$ was considered significant.

Informed consent was obtained from the parents or legal guardians of the children. Institutional Review Board approval was obtained from the Health Research Ethics Committee at Stellenbosch University.

\section{Results \\ Clinical features}

Fifty-six children were studied. Table 1 shows the baseline demographic and clinical characteristics. Median age was 5 years. Of the 36 cases previously hospitalised for pneumonia, 27 (74\%) had two or more and
13 (37\%) had three or more hospitalisations. The majority $(93 \%)$ had been previously treated for PTB, $60 \%$ on two or more occasions. Forty-seven per cent were stunted and $31 \%$ were underweight for age.

The median period on ART was 9.8 (IQR 1.1 - 19.5) months. There was documentation of inhaled bronchodilator use in 8 $(16 \%)$ and inhaled corticosteroids in $5(10 \%)$ children.

\section{Lung function}

Twenty-seven children (48\%) performed adequate lung function tests. The median $\mathrm{FEV}_{1} \%$ was $60 \%$ (IQR 45.3 - 86.3\%). Only

Table 1. Demographic data, background information, associated diagnoses and laboratory findings of HIV-infected children $(N=56)$

\begin{tabular}{|c|c|c|}
\hline Demographic data & Total group, $\boldsymbol{n}^{*}(\%)$ & Lung functions only, $n$ (\%) \\
\hline Total & 56 & 27 \\
\hline Age (years), median (IQR) & $5(2-8)$ & $6(3-8)$ \\
\hline Gender (male) & $30(53.6)$ & $13(48.2)$ \\
\hline \multicolumn{3}{|l|}{ Background information } \\
\hline Pneumonia requiring hospitalisation & $36(64.0)$ & $15(55.6)$ \\
\hline Previous TB & $50 / 54(92.6)$ & $25(92.6)$ \\
\hline Exercise limitation & $28 / 53(52.8)$ & $17(65.4)$ \\
\hline Wheezing & $35 / 54(64.8)$ & $16(59.3)$ \\
\hline Snoring & $23 / 49(46.9)$ & $12(50.0)$ \\
\hline Any smoking exposure at home & $24 / 53(45.3)$ & $13(48.2)$ \\
\hline Recurrent pneumonia & $25 / 53(47.2)$ & $10(40.0)$ \\
\hline \multicolumn{3}{|l|}{ Clinical characteristics } \\
\hline Dental caries & $14 / 40(35.0)$ & $6(33.3)$ \\
\hline Digital clubbing & $23 / 52(44.2)$ & $13(52.0)$ \\
\hline WAZ, median (IQR) & $-1.92(-2.65--0.77)$ & $-1.45(-2.95--0.46)$ \\
\hline HAZ, median (IQR) & $-1.39(-2.16--0.73)$ & $-1.40(-2.15--0.85)$ \\
\hline WHZ, median (IQR) & $0.09(-0.82-0.65)$ & $0.01(-0.80--0.70)$ \\
\hline Wheeze & $5 / 54(9.3)$ & $3(11.5)$ \\
\hline Hyperinflation & $28 / 52(53.8)$ & $14(56.0)$ \\
\hline Respiratory rate ratio, median (IQR) & $1.10(0.96-1.36)$ & $1.16(0.80-1.36)$ \\
\hline \multicolumn{3}{|l|}{ Associated diagnoses } \\
\hline Gastro-oesophageal reflux & $5 / 53(9.4)$ & $2(8.0)$ \\
\hline Failure to thrive & $11 / 52(21.2)$ & $6(24.0)$ \\
\hline Developmental delay & $9 / 53(17.0)$ & $4(16.0)$ \\
\hline Hyperpigmented skin lesions & $15 / 51(29.4)$ & $7(29.2)$ \\
\hline Asthma & $8 / 56(14.3)$ & $7(25.9)$ \\
\hline LIP & $28 / 52(53.8)$ & $18(75)$ \\
\hline \multicolumn{3}{|l|}{ Laboratory } \\
\hline CD4\%, median (IQR) & $13(8.5-16)$ & $13(8.5-15.8)$ \\
\hline VL (log), median (IQR) & $5.84(4.97-6.48)$ & $5.94(5.58-6.54)$ \\
\hline $\begin{array}{l}\text { WAZ = observed weight }- \text { median weight of the } \\
\text { population; } \mathrm{HAZ}=\text { observed height }- \text { median } \\
\text { reference population. } \\
{ }^{*} \text { Equation used where denominator differed frot }\end{array}$ & $\begin{array}{l}\text { eference population / stand } \\
\text { ght of the reference popula }\end{array}$ & $\begin{array}{l}\text { rd deviation value of reference } \\
\text { on / standard deviation value of } \\
\text { study }(N=56) \text {. }\end{array}$ \\
\hline
\end{tabular}


5 (18.5\%) had a positive bronchodilator response $\left(\mathrm{FEV}_{1} \%\right.$ increase $\geq 12 \%$ post bronchodilator). Clinical signs associated with $\mathrm{FEV}_{1} \%$ in a univariate relationship included admission for pneumonia, respiratory rate, clubbing, hyperinflation and hyperpigmented skin lesions. There was a significant negative association between respiratory rate (respiratory rate ratio) and lung function $\left(\mathrm{FEV}_{1} \%\right)$, indicating that a higher respiratory rate was associated with lower $\mathrm{FEV}_{1} \%$ (Fig. 1). All but one child with $\mathrm{FEV}_{1} \%<60 \%$ predicted had a respiratory rate at the upper limit of normal for age (respiratory rate ratio $>1$ ).

The final regression model for clinical signs associated with lung function outcome $\left(\mathrm{FEV}_{1} \%\right)$ is shown in Table $2(p<0.001$, adjusted $R^{2}=0.68$ ). Although respiratory rate ratio was not statistically significant in the final model $(p=0.10)$, it was retained owing to its clinical relevance and the significant univariate relationship with

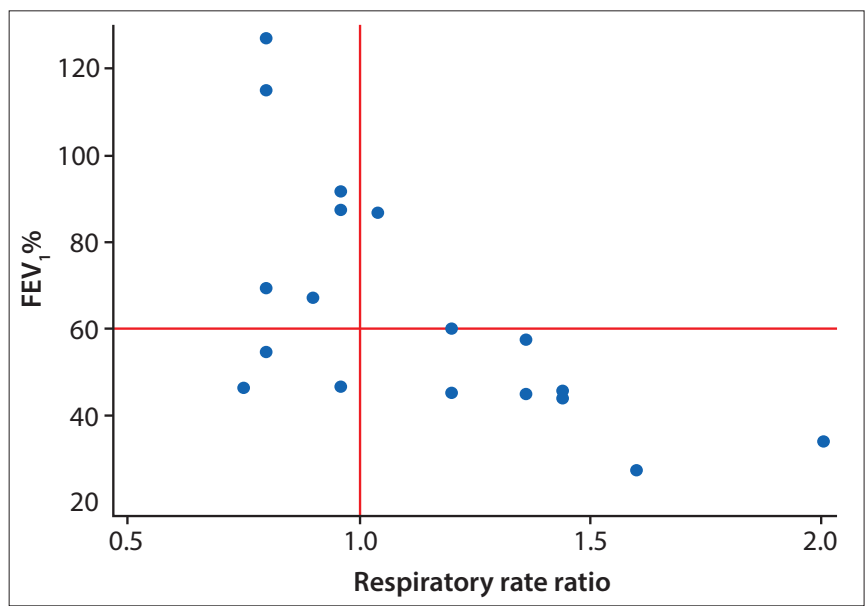

Fig. 1. Scatter plot of $F E V_{1} \%$ v. respiratory rate ratio (correlation coefficient $=$ $-0.53, p=0.007$ ).

Table 2. Relationship between $\mathrm{FEV}_{1} \%$ and clinical variables

\begin{tabular}{lll}
\hline Variable & $\begin{array}{l}\text { Test statistic / } \\
\text { mean difference } \\
(\mathbf{9 5 \%} \text { CI) }\end{array}$ & p-value \\
\hline Respiratory rate ratio & -0.65 & 0.007 \\
WAZ & 0.09 & 0.702 \\
HAZ & 0.31 & 0.148 \\
WHZ & 0.25 & 0.262 \\
VL (log) & 0.06 & 0.881 \\
CD4\% & 0.35 & 0.089 \\
Age & -0.01 & 0.958 \\
cART duration & -0.05 & 0.801 \\
Admitted for pneumonia & $20.5(2.2-38.9)$ & 0.030 \\
Exercise limitation & $14.8(-5.8-55.4)$ & 0.152 \\
Snoring & $8.8(-13.1-29.5)$ & 0.423 \\
Clubbing & $20.2(1.0-39.4)$ & 0.040 \\
Wheezing & $-10.3(-30.3-9.7)$ & 0.298 \\
Hyperinflation & $25.0(6.5-43.5)$ & 0.010 \\
LIP & $18.1(-6.5-42.6)$ & 0.141 \\
Hyperpigmented skin lesions & $22.9(0.8-45.0)$ & 0.043 \\
*Spearman rank correlation reported for continuous variables and mean difference \\
(95\% CI) reported for categorical variables.
\end{tabular}

$\mathrm{FEV}_{1} \%$. A unit increase in respiratory rate ratio, in the absence of other risk factors, was associated with a $26 \%$ reduction of estimated $\mathrm{FEV}_{1} \%$. The presence of hyperinflation, in the absence of other risk factors, was associated with a $40 \%$ reduction in estimated $\mathrm{FEV}_{1} \%$. Hyperpigmented skin lesions alone, an easily recognisable clinical marker, was associated with a $34 \%$ reduction in $\mathrm{FEV}_{1} \%$. The predictive values of hyperpigmented skin lesions and hyperinflation are not unique as there is significant interaction between these factors. $\mathrm{FEV}_{1}$ in one subject, having high influence relative to all other observations, was determined to be an outlier. After refitting the regression model without this observation, our substantive conclusions did not change (adjusted $R^{2}=0.82, p<0.001$ ). However, respiratory rate ratio reached statistical significance $(p=0.018)$. The outlier observation was retained in the final regression model.

\section{Discussion}

There are very few clinical descriptors of clinical and lung function parameters in HIV-infected children with CLD. This study highlights uniformly poor lung function and some clinical markers for poor respiratory function in these children. Multiple linear regression analyses indicate that ratios comparing respiratory rate with the upper limit of normal for age, hyperinflation and hyperpigmented skin lesions are potential indicators of poor lung function.

The epidemiology of CLD in HIV-infected children and adolescents is poorly described. Ferrand et al..$^{[5]}$ reported an $86 \%$ prevalence of CLD in Zimbabwean adolescent survivors of perinatal HIV infection. Rylance et al. ${ }^{[19]}$ similarly described respiratory impairment in a group of Malawian HIV-infected adolescents. Our case series is in pre-adolescents, suggesting that CLD is already well established in childhood. Children and adolescents with CLD most likely represent 'slow progressors' with a more gradual onset of immunosuppression after perinatal infection.

PTB was the most frequent comorbid illness in our study (92\%), with most $(60 \%)$ requiring anti-TB treatment on two or more occasions. Neither the temporal relationship between PTB and CLD nor the accuracy of the PTB diagnosis could be established. In adolescents with CLD, small-airway disease with concomitant bronchiectasis was the main pathological abnormality, more frequent than PTB and LIP. ${ }^{[5]}$ Overdiagnosis of PTB could account for the high prevalence of previous PTB in our study.

Clinicians should be alerted to identifying HIV-infected children and adolescents at increased risk of CLD. Factors identified in the history of the patient include a background of recurrent respiratory tract infections ( $47 \%$ in our study) or pneumonia. Similarly, in a case-controlled study evaluating risk factors for bronchiectasis in HIV-infected children, $89.5 \%$ of those with bronchiectasis had a history of recurrent pneumonia v. $8.8 \%$ in the control group $(p \leq 0.001) .{ }^{[20]}$ Additional aggravating factors identified were exposure to tobacco smoke (46\%), dental caries (30\%) and gastro-oesophageal reflux (7\%), all being opportunities for intervention to limit further lung damage. In a recent review we discussed the challenges of CLD and some potential treatments, such as aggressive antibiotic therapy and regular immunisations. ${ }^{[21]}$

Table 3. Final model for multivariable linear regression analysis of factors associated with reduced $\mathrm{FEV}_{1} \%$ in $\mathrm{HIV}$-infected children

\begin{tabular}{|c|c|c|}
\hline Variable & $\beta(95 \% \mathrm{CI})$ & $p$-value \\
\hline Respiratory rate ratio & $-25.7(-57.4-5.87)$ & 0.103 \\
\hline Hyperinflation & $-40.5(-59.6--21.3)$ & 0.000 \\
\hline Hyperpigmented skin lesions & $-33.5(-56.8--10.2)$ & 0.008 \\
\hline $\begin{array}{l}\text { Hyperinflation and } \\
\text { hyperpigmented skin lesions }\end{array}$ & $38.8(3.80,73.8)$ & 0.032 \\
\hline
\end{tabular}


In the current study, $53 \%$ of patients had a history of impaired effort tolerance, similar to that reported in HIV-infected adolescents. ${ }^{[5,15]}$ Other associated symptoms included previous wheezing (65\%) and snoring (47\%). A significant proportion ( $>40 \%)$ of HIV-infected adolescents with CLD had hypoxia, either at rest or with exercise. ${ }^{[5,14]}$ In addition, Ferrand et al. ${ }^{[5]}$ documented echocardiographic evidence of pulmonary hypertension in 7\% of adolescents with CLD. Additional cardiac abnormalities are common in HIV-infected adolescents, with $67 \%$ having echocardiographic evidence of left ventricular hypertrophy. ${ }^{[22]}$ Hypoxia and cardiac involvement are common in HIV-infected children and adolescents, and their evaluation should be a major priority.

Our case series most likely represents the worst end of the spectrum, given that the median $\mathrm{FEV}_{1} \%$ of $60 \%$ of the expected value was used as the 'norm' for comparison. It is likely that routine lung function tests and more sensitive tests of exercise impairment will identify more subtle effort intolerance. This study identified useful clinical associations with poor lung function, i.e. respiratory rate, hyperinflation and hyperpigmented skin lesions. Of note, the degree of immunosuppression (CD4\%) and VL were not associated with lung function in this study as in other paediatric adolescent studies. ${ }^{[5,22]}$ The origin of the hyperpigmentation is uncertain and could represent many causes, such as impetigo, papular pruritic eruption and fungal infections. In our experience, papular pruritic eruption occurs commonly in HIV-infected children, and it is a stage 2 WHO criterion frequently seen with more advanced disease and immunosuppression. ${ }^{[23-25]}$ The clinical signs identified could be additional pointers to CLD, alerting clinicians to a need for further investigation. The absence of a bronchodilator response, in $81.5 \%$ in our series, has been noted elsewhere and supports the diagnosis of non-reversible small-airway disease. ${ }^{[18]}$

The role of cART and other medications in managing and preventing CLD requires further study. Although the duration of cART did not correlate with lung function in earlier studies, it is likely that very early initiation will limit development of CLD. ${ }^{[26]}$

Despite the limitations in our study, such as no control group and a non-random sample with a referral bias, we provide data on HIV-related CLD in children, emphasising the ubiquity of poor lung function, irreversible in the majority ( $82 \%)$ of children in our study. The strength of this study is the use of an objectively assessed outcome measure in multivariate analyses, viz. the $\mathrm{FEV}_{1}$. We further identified clinical signs associated with poor lung function.

\section{Conclusion}

We documented poor, often irreversible lung function in HIV-infected children evaluated for CLD. Easily assessed clinical signs, i.e. respiratory rate, hyperinflation and pigmented skin lesions, should alert clinicians to considering CLD in HIV-infected children and adolescents.

Acknowledgements. The authors are thankful for the parents and their children who agreed to participate in this study. We thank Mrs Beulah Hill for coordinating the project and Emeritus Prof. William Pick for reviewing the manuscript. We are also grateful to the Tygerberg Children's Hospital and KID-CRU, where the project was conducted.

\section{References}

1. UNAIDS. Global Report UNAIDS Report on the Global AIDS Epidemic 2010. Geneva: UNAIDS, 2010
2. Steinbrook R. The AIDS epidemic in 2004. N Engl J Med 2004;351(2):115-117. [http://dx.doi.org/10.1056/NEJMp048156]

3. National Department of Health South Africa. Guidelines for the Management of HIV in Children. 2010. 2nd ed. http://www. sahivsoc.org/upload/documents/Guidelines_for_Management_of_ HIV in_Children_2010.pdf (accessed 16 February 2014).

4. Graham SM, Gibb DM. HIV disease and respiratory infection in children. $\mathrm{Br}$ Med Bull 2002;61:133-150.

5. Ferrand RA, Desai SR, Hopkins C, et al. Chronic lung disease in adolescents with delayed diagnosis of vertically acquired HIV infection. Clin Infect Dis 2012;55(1):145-152. [http://dx.doi.org/10.1093/cid/cis271]

6. Sheikh S, Madiraju K, Steiner P, Rao M. Bronchiectasis in pediatric AIDS. Chest 1997:112(5):1202-1207.

7. Jeena PM, Coovadia HM, Thula SA, Blythe D, Buckels NJ, Chetty R. Persistent and chronic lung disease in HIV-1 infected and uninfected African children. AIDS 1998;12(10):1185-1193.

8. Jeena PM, Coovadia HM, Hadley LG, Wiersma R, Grant H, Chrystal V. Lymph node biopsies in HIV-infected and non-infected children with persistent lung disease. Int J Tuberc Lung Dis 2000;4(2):139-146.

9. Sharland M, Gibb DM, Holland F. Respiratory morbidity from lymphocytic interstitial pneumonitis (LIP) in vertically acquired HIV infection. Arch Dis Child 1997;76(4):334-336

10. Berdon WE, Mellins RB, Abramson SJ, Ruzal-Shapiro C. Pediatric HIV infection in its second decade: The changing pattern of lung involvement. Clinical, plain film, and computed tomographic findings. Radiol Clin North Am 1993;31(3):453-463.

11. Norton KI, Kattan M, Rao JS, et al. Chronic radiographic lung changes in children with vertically transmitted HIV-1 infection. Am J Roentgenol 2001;176(6):1553-1558. [http://dx.doi.org/10.2214/ajr.176.6.1761553]

12. Zar HJ. Chronic lung disease in human immunodeficiency virus (HIV) infected children. Pediatr Pulmonol 2008;43(1):1-10. [http://dx.doi.org/10.1002/ ppul.20676]

13. Graham SM, Coulter JB, Gilks CF. Pulmonary disease in HIV-infected African children. Int J Tuberc Lung Dis 2001;5(1):12-23.

14. Pitcher RD, Lombard C, Cotton MF, Beningfield SJ, Zar HJ. Clinical and immunological correlates of chest X-ray abnormalities in HIV-infected South African children with limited access to anti-retroviral therapy. Pediatr Pulmonol 2014;49(6):581-588. [http://dx.doi.org/10.1002/ppul.22840]

15. World Health Organization (WHO). Physical status: The use and interpretation of anthropometry: Report of a WHO Expert Committee. WHO Technical Report Series No. 854. Geneva: WHO, 1995.

16. Miller MR, Hankinson J, Brusasco V, et al. Standardisation of spirometry. Eur Respir J 2005;26(2):319-338. [http://dx.doi.org/10.1183/09031936.05.00034805]

17. Polgar G, Promadhat V. Pulmonary function testing in children: Techniques and standards. Philadelphia: Saunders, 1971.

18. Harrison VC. Handbook of Paediatrics in Developing Countries. Cape Town: Oxford University Press, 2004.

19. Rylance J, Mwalukomo T, Rylance S, et al. Lung function and bronchodilator response in perinatally HIV-infected adolescents: Malawi. In: Programs and Abstracts of the 19th Conference on Retroviruses and Opportunistic Infections (CROI 2012). Seattle, 2012.

20. Berman DM, Mafut D, Djokic B, Scott G, Mitchell C. Risk factors for the development of bronchiectasis in HIV-infected children. Pediatr Pulmonol 2007;42(10):871-875. [http://dx.doi.org/10.1002/ppul.20668]

21. Weber HC, Gie RP, Cotton MF. Review: The challenge of chronic lung disease in HIV-infected children and adolescents. J Int AIDS Soc 2013;16:18633. [http://dx.doi.org/10.7448/IAS.16.1.18633]

22. Miller RF Kaski JP, Hakim J, et al. Cardiac disease in adolescents with delayed diagnosis of vertically acquired HIV infection. Clin Infect Dis 2013;56(4):576582. [http://dx.doi.org/10.1093/cid/cis911]

23. Wananukul S, Deekajorndech T, Panchareon C, Thisyakorn U. Mucocutaneous findings in pediatric AIDS related to degree of immunosuppression. Pediatr Dermatol 2003;20(4):289-294

24. Nnoruka EN, Chukwuka JC, Anisuiba B. Correlation of mucocutaneous manifestations of HIV/AIDS infection with CD4 counts and disease progression. Int J Dermatol 2007;46(Suppl 2):14-18. [http://dx.doi.org/10.1111/ j.1365-4632.2007.03349.x]

25. Baveewo S, Ssali F, Karamagi C, et al. Validation of World Health Organization HIV/AIDS clinical staging in predicting initiation of antiretroviral therapy and clinical predictors of low CD4 cell count in Uganda. Plos One 2011;6(5):e19089. [http://dx.doi.org/10.1371/journal.pone.0019089]

26. Cotton MF, Violari A, Otwombe K, et al. Early time-limited antiretroviral therapy versus deferred therapy in South African infants infected with HIV: Results from the children with HIV early antiretroviral (CHER) randomised trial. Lancet 2013;382:1555-1563. [http://dx.doi.org/10.1016/ S0140-6736(13)61409-9] 